\title{
Cenozoic dynamics of shallow-marine biodiversity in the Western Pacific
}

Moriaki Yasuhara (University of Hong Kong), Hokuto Iwatani (University of Hong Kong), Gene Hunt (Smithsonian Institution), Hisayo Okahashi (University of Hong Kong), Tomoki Kase (National Museum of Nature and Science, Japan), Hiroki Hayashi (Shimane University), Toshiaki Irizuki (Shimane University), Yolanda M. Aguilar (Marine Geological Survey, Philippines), Allan Gil S. Fernando (University of Philippines), Willem Renema (Naturalis Biodiversity Center)

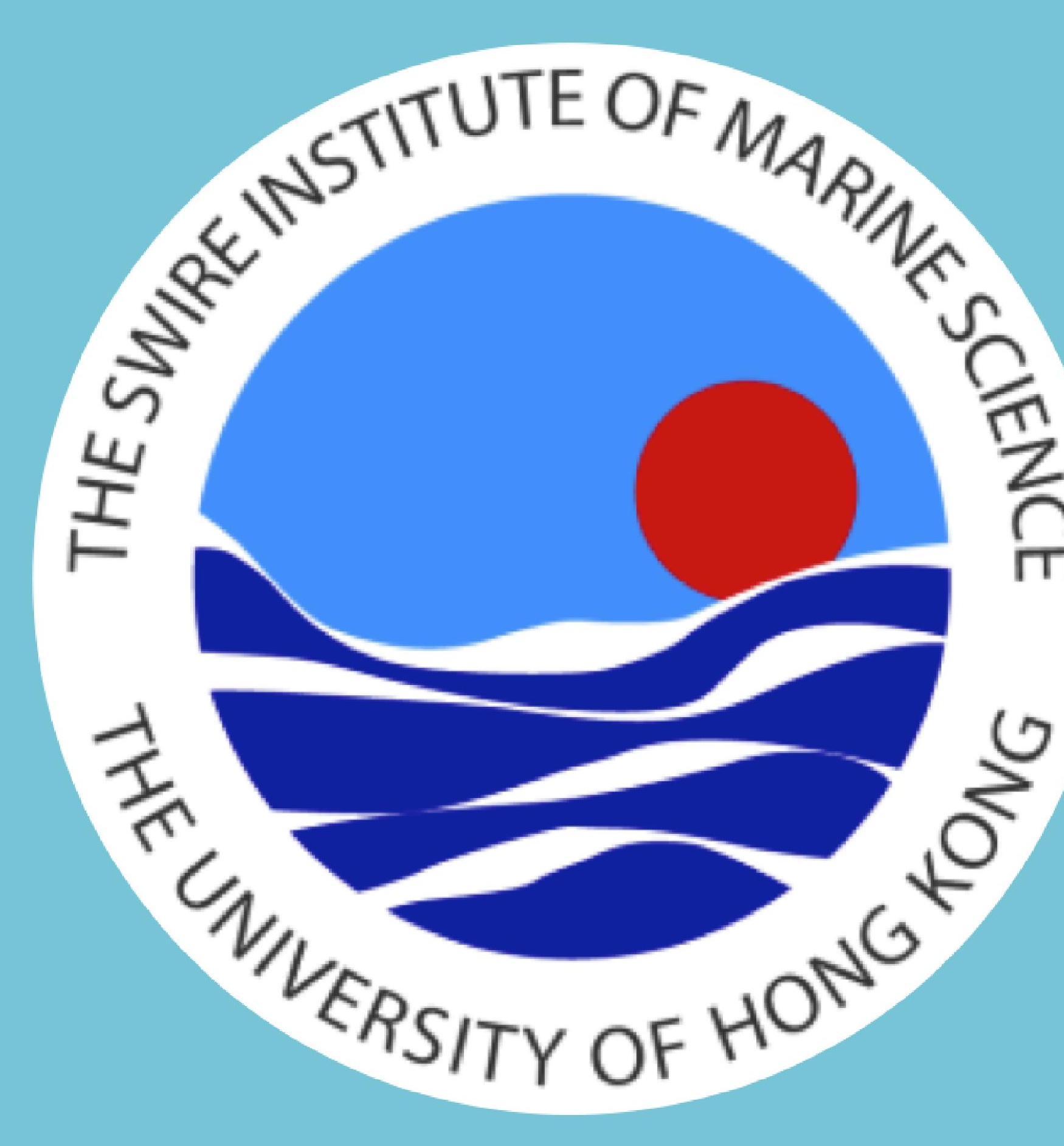

moriakiyasuhara@gmail.com or yasuhara@hku.hk

Aim Cenozoic dynamics of large-scale species diversity patterns remain poorly understood, especially for the Western Pacific, in part because of the paucity of well-dated fossil records from the tropics. This article aims to reveal the spatiotemporal dynamics of species diversity in the Western Pacific through the Cenozoic, focusing on the tropical Indo-Australian Archipelago (IAA) biodiversity hotspot.

Location Tropical and north-western Pacific Ocean.

Methods We analysed well-preserved fossil ostracodes from the tropical Western Pacific and combined their diversity data with other published data from the region to reconstruct Cenozoic dynamics of species diversity in the tropical and north-western Pacific Ocean. We fitted generalized additive models to test for differences in richness over time and across geographical regions while accounting for sample-size variation among samples.

Results Low-, mid- and high-latitude regions all show a similar diversity trajectory: diversity is low in the Eocene and Oligocene, increases from the Early Miocene to the Plio-Pleistocene but then declines to the present day. Present-day high biodiversity in these regions was established during the Pliocene with a remarkable diversity increase at that time. Latitudinal diversity patterns are relatively flat and never show a simple decline from the tropics to higher latitudes.

Main conclusions Western Pacific Cenozoic ostracodes exhibit a spatiotemporal pattern of species diversity that is inconsisten with the commonly reported and persistent pattern of declining diversity from the tropics to the extratropics. While this inconsistency could be interpreted as evidence that ostracodes are a contrarian clade, Atlantic ostracodes display a standard latitudinal species diversity gradient. Contrasting patterns between oceans species diversity gradient. Contrasting patterns between oceans ics and temporal geomorphological dynamics) in shaping the biodiversity of the Western Pacific.

Keywords biodiversity hotspot, Cenozoic, Coral Triangle, IndoAustralian Archipelago, latitudinal diversity gradients, Ostracoda, temporal diversity dynamics, tropical shallow-marine biodiversity, Western Pacific.

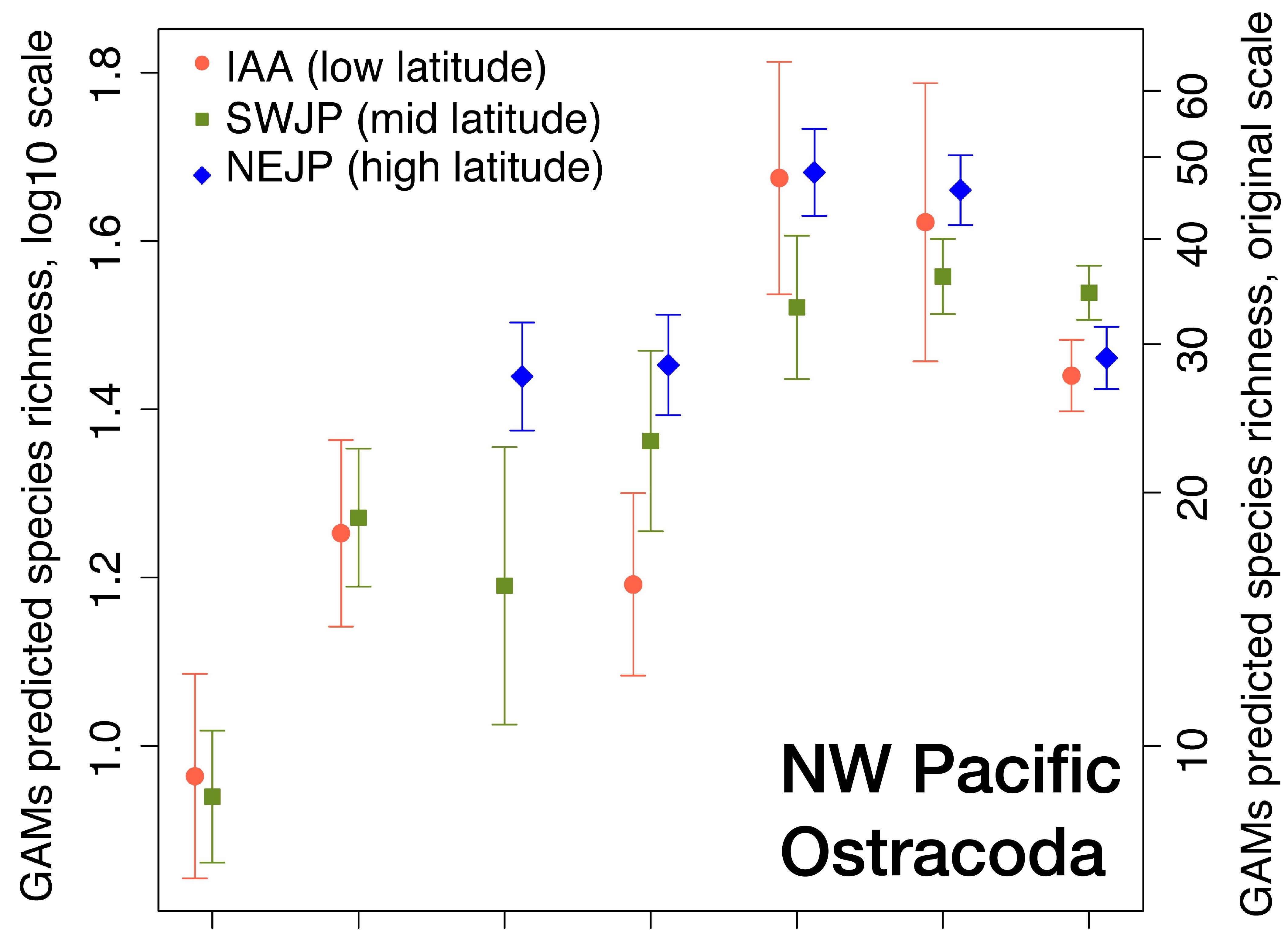

Fig. on the left: Northwestern Pacific Ostracod diversity trajectories over time for the three regions of Indo-Australian Archipelago (IAA) southwestern Japan (SWJP) and northeastern Japan (NEJP), based on species richness from GAMs (generalized additive models). This figure shows model-predicted species richness at
$n=200$ individuals for all combinations of time period and region for which we have data. Error bars show the $95 \%$ confidence interval around predicted richness. Md: Modern; Pleist: Pleistocene; Plio: Pliocene; LMio: Late Miocene; MMio: Eocene-Oligocene.

Eo-Olig EMio MMio LMio Plio Pleist Md Time period
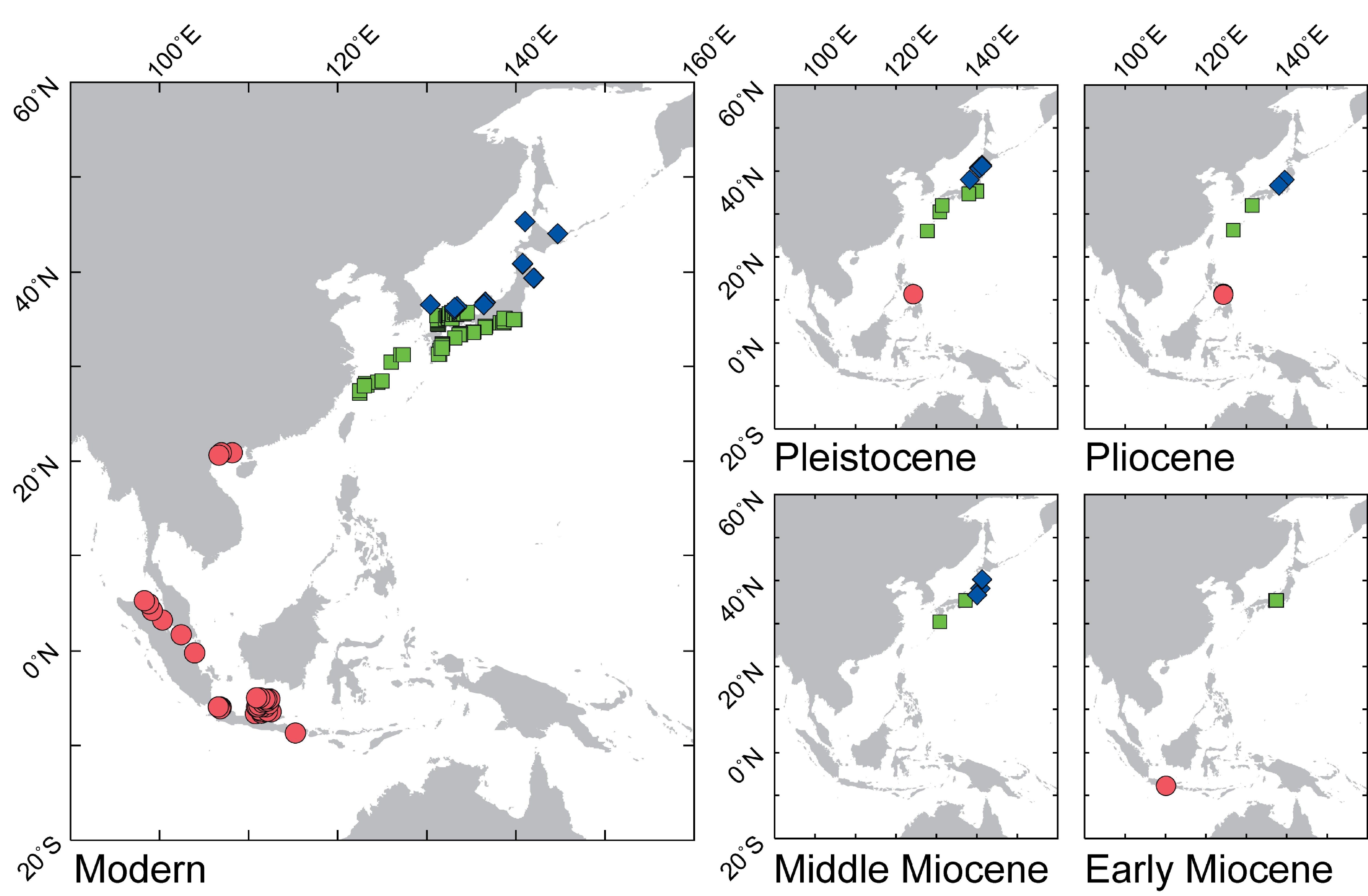

Pliocene
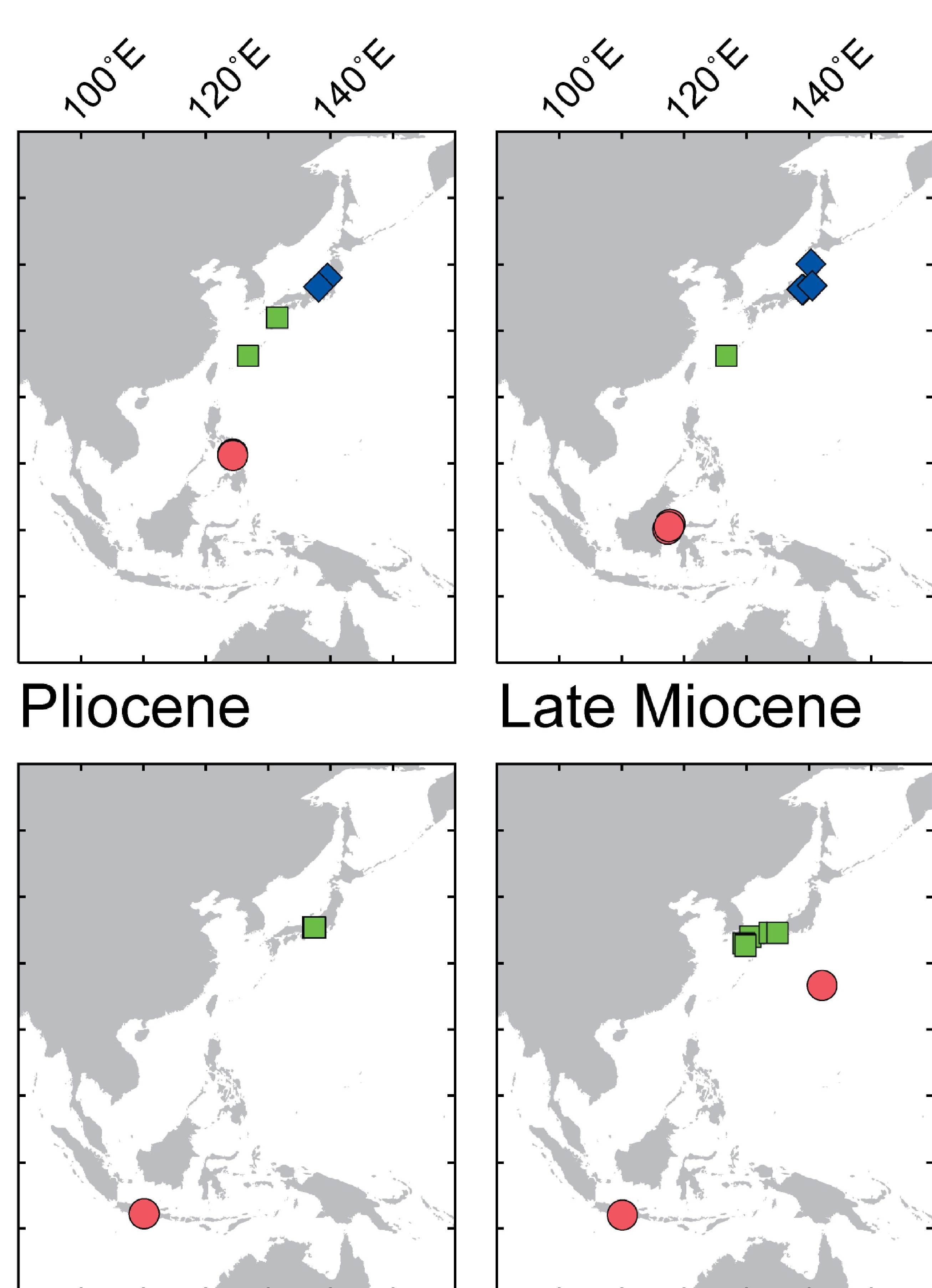

Late Miocene

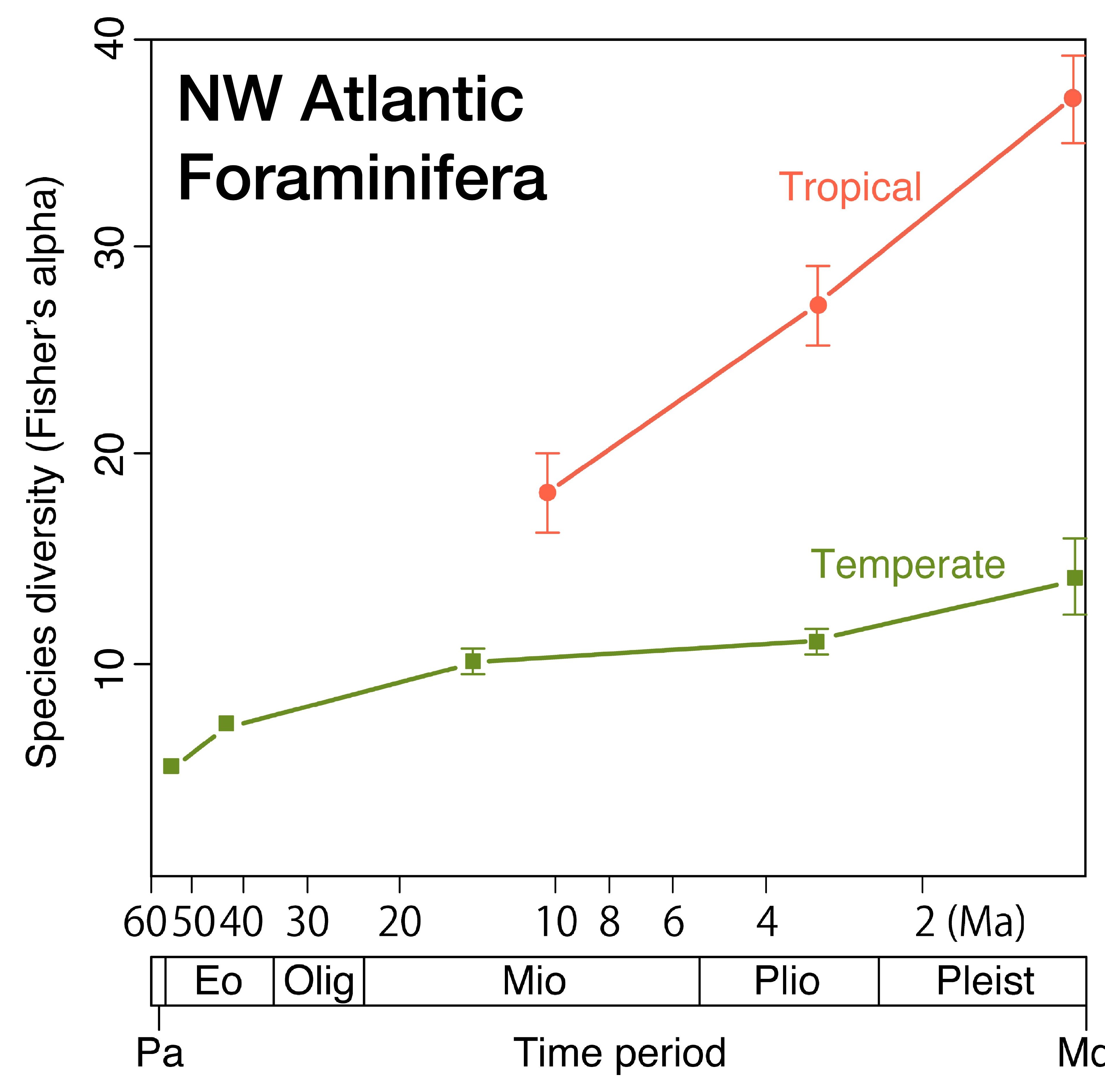

Fig. above: Northwestern Atlantic Foraminiferal diversity trajectories over time for tropical and temperate regions, based on Flsher's alpha diversity index (Buzas et al 2002. atitudinal difference in biodiversity caused by higher tropical rate of increase. PNAS).

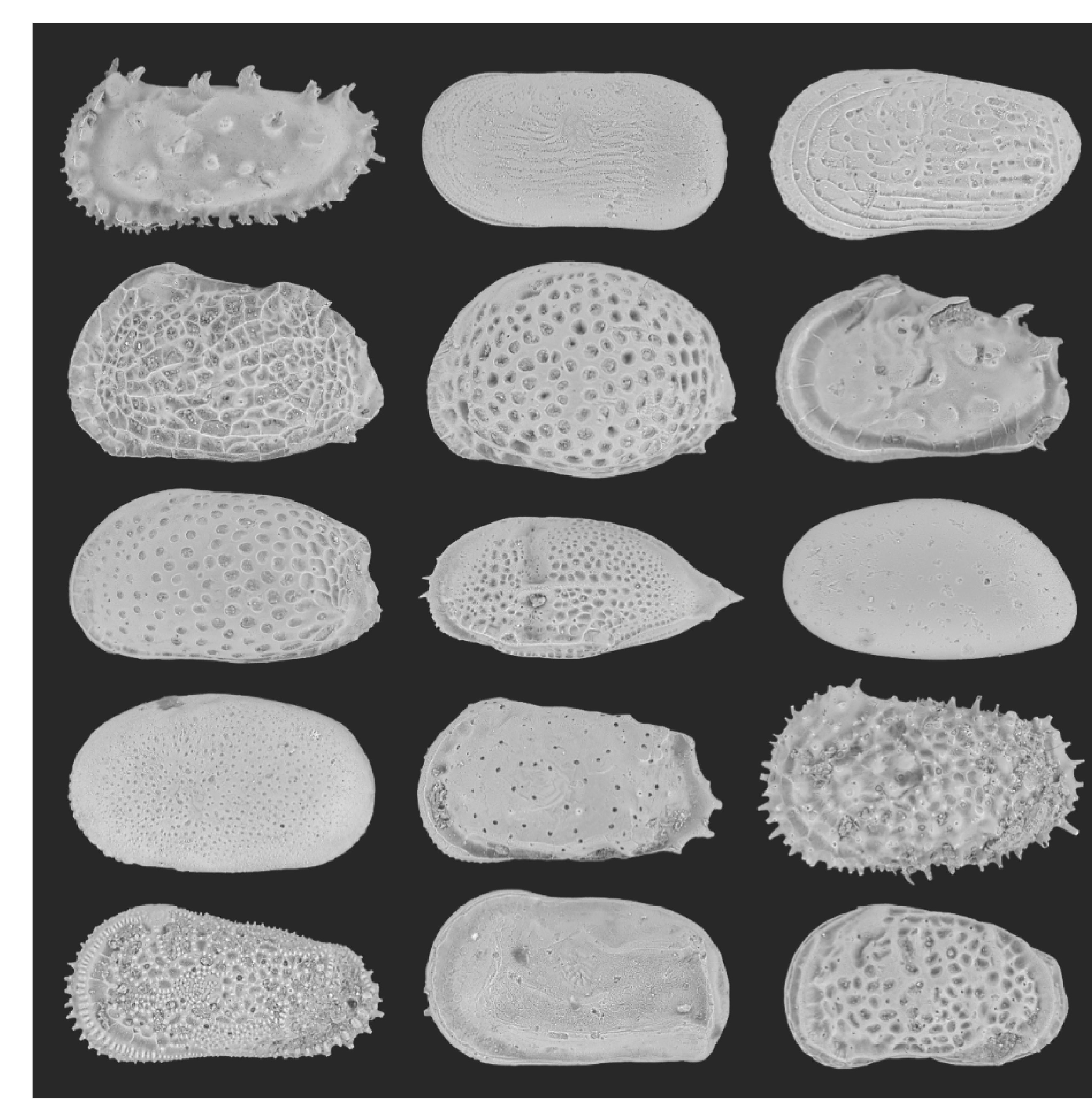

Fig above: Locality maps of ostracod samples. Red circle: Indo-Australian Archipelago (IAA). Green square: south-western Japan (SWJP). Blue rhombus: northeastern Japan (NEJP). 